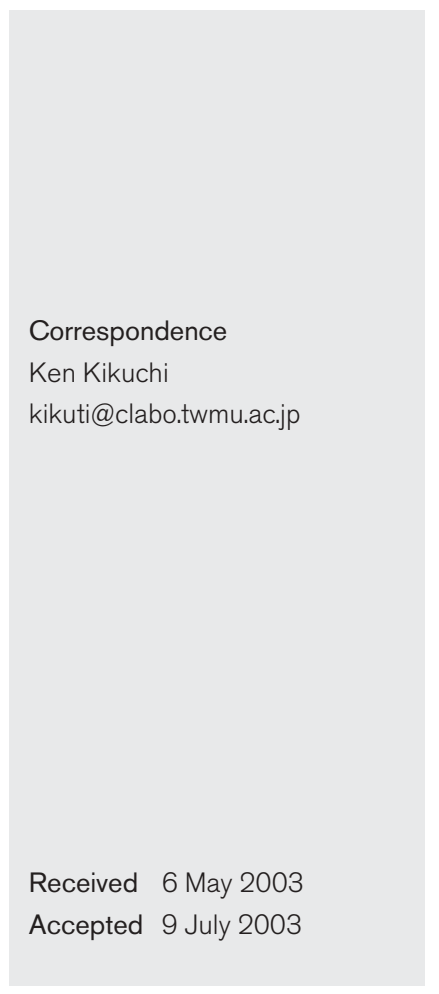

\title{
Evaluation of a new serotyping kit for Streptococcus pneumoniae
}

\author{
Mildred Anyango Mudany, ${ }^{1,2}$ Ken Kikuchi, ${ }^{1}$ Kyoichi Totsuka ${ }^{1}$ and \\ Takehiko Uchiyama ${ }^{1,2}$
}

Department of Infectious Diseases ${ }^{1}$ and Department of Microbiology and Immunology ${ }^{2}$, Tokyo Women's Medical University, 8-1 Kawada-cho, Shinjuku-ku, Tokyo, 162-8666, Japan

\begin{abstract}
A new serotyping test kit (Streptococcus pneumoniae antisera 'Seiken' set; Denka kit) was evaluated for $\mathbf{2 8 5}$ strains of Streptococcus pneumoniae in comparison with the standard capsular reaction (Quellung test). This new kit is based on the slide-agglutination method and is composed of eight pool sera, 40 group or type sera and 41 specific type sera. All serotyping results by using the Denka kit were completely identical to those obtained by using the conventional Quellung test. For types and groups, sensitivity and specificity were 100 and $100 \%$, respectively. For specific types, sensitivity and specificity were 100 and $100 \%$, respectively. The Denka kit is relatively rapid (mean test time, 5 min, versus 15 min by Quellung test), cheap ( 0.5 US $\$$ per test, versus 1.4 US $\$$ per Quellung test), easy to perform and does not require special equipment. The Denka kit may be useful for fieldworkers in developing countries involved in epidemiological surveys and vaccine development.
\end{abstract}

\section{INTRODUCTION}

Streptococcus pneumoniae is a major community-acquired pathogen that causes serious pneumonia, otitis media, septicaemia and meningitis worldwide (Roberts, 1979). In adults, types $1-8$ are responsible for about $75 \%$ of pneumococcal pneumonia cases and for more than half of pneumococcal bacteraemia cases, whereas in children, types 6, 14, 19 and 23 are frequently responsible (Brooks et al., 1998). Infections caused by $S$. pneumoniae can be lifethreatening, particularly to children aged $<2$ years; the highest risk is to children aged 0-11 months and elderly people (Cant, 2002).

Pneumococcal vaccines are made from purified capsular polysaccharides. More than 90 capsule types and serotypes are known in S. pneumoniae (Hausdorff et al., 2002). The polysaccharide vaccine for $S$. pneumoniae (Pneumovaccus ${ }^{\mathrm{R}}$ ) is composed of 23 different capsule antigens. This vaccine is very useful for prevention of pneumococcal infection in adults. However, in children aged $<2$ years, the acquisition rate of immunity to $S$. pneumoniae is insufficient because of low immunogenic activity of the bacterium and premature immunity of the subjects (Hausdorff et al., 2000). Several new conjugated pneumococcal vaccines have been developed, but the antigens selected for these vaccines are limited to only 7, 9 or 11 different serotypes, mainly of penicillin-

Abbreviations: CIEP, counterimmunoelectrophoresis; COA, coagglutination; LA, latex agglutination. resistant S. pneumoniae (Joloba et al., 2001). Serotyping of $S$. pneumoniae is very important for epidemiological analysis and pneumococcal vaccination.

The capsular reaction (Quellung test) is the gold standard used to determine serotypes of S. pneumoniae (Sorensen, 1993). It is very reliable and reproducible, but is also labourintensive and not easily affordable. Denka Seiken has developed a new method (Streptococcus pneumoniae antisera 'Seiken' set; Denka kit) based on slide-agglutination, which is cheap, simple, rapid and reliable. We evaluated this kit for epidemiological surveys of $S$. pneumoniae.

\section{METHODS}

Bacterial strains and culture methods. In total, 285 strains of $S$. pneumoniae were used (130 from Nepal and 155 from Japan). These isolates were stored at $-85^{\circ} \mathrm{C}$ in $10 \%$ skimmed milk until use. Each strain was maintained on Columbia agar with $5 \%$ sheep blood at $35{ }^{\circ} \mathrm{C}$ for $16 \mathrm{~h}$ in $5 \% \mathrm{CO}_{2}$. S. pneumoniae was identified by conventional methods, including optochin susceptibility and bile solubility tests (Doern et al., 1999). These identification results were confirmed by PCR amplification of lytA, the pneumococcal-specific autolysin gene (Nagai et al., 2001).

Quellung test. The Quellung test was performed as described previously by using anti-pneumococcal capsule serum from the Statens Serum Institute, Denmark (Lund \& Henrichsen, 1978; Sorensen, 1993).

Slide-agglutination method for serotyping. The Denka kit is supplied by Denka Seiken. It is intended for determination of S. pneumoniae serotypes. 
Sera were prepared by hyperimmunizing healthy rabbits with standard strains of known serotypes of pneumococci, which were obtained from the American Type Culture Collection (ATCC). After bleeding, antisera were separated, heated at $56{ }^{\circ} \mathrm{C}$ for $30 \mathrm{~min}$, absorbed to remove crossagglutinins and sterilized by antibacterial filtration.

The Denka kit is composed of eight pool sera, 40 group or type sera and 41 specific type factor sera. The first kit contains eight vials of polyvalent (pool) antisera and 40 vials of monovalent group or type antisera. The Denka kit covers all vaccine types and several major non-vaccine types of pneumococci (Table 1). Pool sera recognize several antigens, which are serogroups or types within each pool. For example, pool 1 recognizes pneumococcal antigens types 1,2,3,4 and 5, whilst pool 2 recognizes 6 , 8,9 and 10 type or group sera. Similarly, pools 3-8 recognize type or group sera as shown (Table 1). Factor sera work on the same principle, but are more specific; they recognize antigens within a particular serotype or group. The second kit contains 41 specific type factor sera (Table 2).

The Denka kit is used as follows. A single colony is obtained after culturing bacteria. A glass slide is divided into several parts for testing the isolate to be typed. A drop $(25 \mu \mathrm{l})$ of each antiserum to be tested is placed onto the respective section of the prepared slide. The same is done for a control with normal saline solution. By using a toothpick or sterile microbacteriological loop, a small but visible amount of bacteria is picked and mixed directly with the drop of antiserum, spreading over the partitioned area. The glass slide is then tilted back and forth to look for agglutination (Fig. 1). Agglutination occurs only when bacteria are mixed with specific sera, which react with bacterial antigens to cause an antigen-antibody reaction if the serotype of the isolate is contained within the antiserum being used. Agglutination that occurs within 1 min can be observed visually and is considered to be a positive reaction (Fig. 2). For the control, bacteria are mixed with physiological saline solution to check if agglutination occurs spontaneously. Reactions are performed at room temperature.

In this study, we first used pool sera to determine the pool to which pneumococci belonged by using the procedure described above. Thereafter, bacteria were tested with each type or group serum within the pool; for instance, if the bacteria agglutinated with pool 1 serum, we next picked bacterial colonies and checked them against type or group sera 1, 2, 3, 4 and 5 (Table 1). Finally, the specific type was checked similarly by using specific type factor sera (Table 2). Some types or groups do not have specific types, e.g. 1, 2, 3, 4, 5, 8, 13, 14, 20, 21, 25, 27, 29, 31, 34, 36, $37,38,39,40,42,43,44,45,46$ and 48 . For these types, the procedure of checking for agglutination stopped at the level of serotype or group. For the rest, we determined the specific type by using specific factor sera that recognized certain antigens or antigenic groups with reactions as shown (Table 2). For example, if a bacterial colony formed agglutination with pool 2 serum and then with type 6 serum, if on further reaction it formed agglutination with specific factor serum $6 b$ and not with $6 c(6 b+6 c-)$, then the specific type is $6 \mathrm{~A}$; the pattern $6 \mathrm{~b}-6 \mathrm{c}+$ would indicate specific type $6 \mathrm{~B}$. Such reactions were carried out for all bacteria tested and patterns of agglutination were interpreted with the aid of the list provided with the kit. Typical slide-agglutination positive and negative controls are shown in Fig. 2.

We also checked the Denka kit for reaction against 18 type strains of streptococci other than pneumococci: Streptococcus agalactiae, Streptococcus anginosus, Streptococcus bovis, Streptococcus canis, Streptococcus constellatus, Streptococcus cristatus, Streptococcus dysgalactiae, Streptococcus gordonii, Streptococcus intermedius, Streptococcus mitis, Streptococcus mutans, Streptococcus oralis, Streptococcus parasanguinis, Streptococcus pyogenes, Streptococcus salivarius, Streptococcus sanguinis, Streptococcus sobrinus and Streptococcus vestibularis.

\section{RESULTS AND DISCUSSION}

All serotyping results for types or groups by the Denka kit were completely identical to those obtained from serotyping by using the conventional Quellung test (Table 3 ). The predominant serotypes were 19, 23, 3, 6, 15, 18 and 11. There was excellent correlation of the results. Sensitivity and specificity were 100 and $100 \%$, respectively.

The results of serotyping for specific types by the Denka kit were identical to those obtained by the Quellung test. Some serogroups, e.g. 3, 4 and 14, do not have specific types. Specific types were determined for 191 pneumococcal strains and there was excellent correlation of the results. The Denka kit cannot distinguish between specific types $9 \mathrm{~A}$ and $9 \mathrm{~V}$ or $24 \mathrm{~B}$ and $24 \mathrm{~F}$. In this study, one pneumococcal strain was identified as $9 \mathrm{~V}$ by the Quellung test and as $9 \mathrm{~A}$ or $9 \mathrm{~V}$ by the Denka kit. Two strains that were identified as $24 \mathrm{~B}$ by the Quellung test were identified by the Denka kit as either 24B or

Table 1. Composition of the Denka kit: pool sera and type or group sera contained

\begin{tabular}{|c|c|c|c|c|c|c|c|c|c|c|}
\hline \multirow[t]{2}{*}{ Pool serum } & \multicolumn{10}{|c|}{ Type or group sera } \\
\hline & \multicolumn{5}{|c|}{ Vaccine-related } & \multicolumn{5}{|c|}{ Non-vaccine-related } \\
\hline 1 & 1 & 2 & 3 & 4 & 5 & & & & & \\
\hline 2 & 6 & 8 & 9 & 10 & & & & & & \\
\hline 3 & 11 & 12 & 14 & 15 & & 16 & & & & \\
\hline 4 & 17 & 18 & 22 & & & 21 & & & & \\
\hline 5 & 20 & 33 & & & & 29 & 31 & 34 & 35 & 47 \\
\hline 6 & 23 & & & & & 25 & 28 & 41 & 46 & \\
\hline 7 & & & & & & 27 & 32 & 36 & 38 & 39 \\
\hline \multirow[t]{2}{*}{8} & 7 & 19 & & & & 24 & 40 & & & \\
\hline & & & & & & $37^{\star}$ & & & & \\
\hline
\end{tabular}

*37 is not included in any of the eight pool sera. 
Table 2. Composition of the Denka kit: specific type factor sera and pattern of reaction to factor sera

\begin{tabular}{|c|c|c|c|c|}
\hline \multirow{2}{*}{$\begin{array}{l}\text { Specific type } \\
\text { Type } 6\end{array}$} & \multicolumn{4}{|c|}{ Reaction to factor serum } \\
\hline & $6 \mathrm{~b}$ & $6 c$ & & \\
\hline $6 \mathrm{~A}$ & + & - & & \\
\hline $6 \mathrm{~B}$ & - & + & & \\
\hline Type 7 & $7 \mathrm{~b}$ & $7 \mathrm{c}$ & $7 \mathrm{e}$ & $7 \mathrm{f}$ \\
\hline $7 \mathrm{~A}$ & + & + & - & - \\
\hline 7B & - & - & + & - \\
\hline 7C & - & - & - & + \\
\hline $7 \mathrm{~F}$ & + & - & - & - \\
\hline Type 9 & $9 \mathrm{~d}$ & $9 \mathrm{e}$ & 9f & \\
\hline $9 \mathrm{~A}$ & + & - & - & \\
\hline $9 \mathrm{~V}$ & + & - & - & \\
\hline $9 \mathrm{~N}$ & - & + & - & \\
\hline $9 \mathrm{~L}$ & - & - & + & \\
\hline Type 10 & $10 \mathrm{~b}$ & $10 \mathrm{c}$ & & \\
\hline $10 \mathrm{~A}$ & - & + & & \\
\hline $10 \mathrm{~F}$ & + & - & & \\
\hline Type 11 & $11 \mathrm{c}$ & $11 \mathrm{f}$ & $11 \mathrm{~g}$ & \\
\hline $11 \mathrm{~A}$ & + & - & - & \\
\hline $11 \mathrm{~B}$ & - & + & + & \\
\hline $11 \mathrm{C}$ & + & + & - & \\
\hline $11 \mathrm{~F}$ & - & - & + & \\
\hline Type 15 & $15 b$ & $15 \mathrm{e}$ & $15 \mathrm{f}$ & $15 \mathrm{~g}$ \\
\hline $15 \mathrm{~A}$ & - & - & - & + \\
\hline $15 \mathrm{~B}$ & + & + & - & - \\
\hline $15 \mathrm{C}$ & - & + & - & - \\
\hline $15 \mathrm{~F}$ & + & - & + & - \\
\hline Type 18 & $18 \mathrm{c}$ & $18 \mathrm{~d}$ & $18 \mathrm{e}$ & $18 \mathrm{f}$ \\
\hline $18 \mathrm{~A}$ & - & + & - & - \\
\hline $18 \mathrm{~B}$ & - & - & + & - \\
\hline $18 \mathrm{C}$ & + & - & + & - \\
\hline $18 \mathrm{~F}$ & + & - & - & + \\
\hline Type 19 & $19 \mathrm{~b}$ & $19 \mathrm{~d}$ & $19 \mathrm{e}$ & $19 \mathrm{f}$ \\
\hline $19 \mathrm{~A}$ & - & + & - & - \\
\hline $19 \mathrm{~B}$ & - & - & + & - \\
\hline $19 \mathrm{C}$ & - & - & - & + \\
\hline $19 \mathrm{~F}$ & + & + & - & - \\
\hline Type 22 & $22 b$ & $22 \mathrm{c}$ & & \\
\hline $22 \mathrm{~A}$ & - & + & & \\
\hline $22 \mathrm{~F}$ & + & - & & \\
\hline Type 23 & $23 \mathrm{~b}$ & $23 c$ & $23 \mathrm{~d}$ & \\
\hline $23 \mathrm{~A}$ & - & + & - & \\
\hline $23 \mathrm{~B}$ & + & - & + & \\
\hline $23 \mathrm{~F}$ & + & - & - & \\
\hline Type 24 & $24 \mathrm{~b}$ & $24 \mathrm{c}$ & & \\
\hline $24 \mathrm{~A}$ & - & + & & \\
\hline $24 \mathrm{~B}$ & + & - & & \\
\hline $24 \mathrm{~F}$ & + & - & & \\
\hline Type 32 & $32 \mathrm{~b}$ & & & \\
\hline $32 \mathrm{~A}$ & + & & & \\
\hline $32 \mathrm{~F}$ & - & & & \\
\hline Type 33 & $20 \mathrm{~b}$ & $33 \mathrm{~b}$ & $33 \mathrm{e}$ & $33 \mathrm{f}$ \\
\hline $33 \mathrm{~A}$ & + & - & - & - \\
\hline $33 \mathrm{~B}$ & - & - & + & + \\
\hline $33 \mathrm{C}$ & - & - & + & - \\
\hline $33 \mathrm{~F}$ & - & + & - & - \\
\hline Type 35 & $20 \mathrm{~b}$ & $29 \mathrm{~b}$ & $35 b$ & $42 \mathrm{a}$ \\
\hline $35 \mathrm{~A}$ & + & - & - & - \\
\hline $35 \mathrm{~B}$ & - & + & - & - \\
\hline $35 \mathrm{C}$ & + & - & - & + \\
\hline $35 \mathrm{~F}$ & - & - & + & - \\
\hline
\end{tabular}

24F (Table 4). In this study, a Quellung result of 9V or 24B was determined to be identical to the Denka result of 9V/9A or $24 \mathrm{~B} / 24 \mathrm{~F}$, respectively.

There was no agglutination with the Denka kit against all 18 type strains of streptococci other than pneumococci. All tested negative with all polyvalent pool sera $1-8$; hence, there was no need for further serotyping.

Since the 1940s, the Streptococcus Unit at Statens Serum Institute, Denmark, has manufactured diagnostic pneumococcal antisera, intended for identification and typing of pneumococci by the capsular reaction test. This method has proved to be reliable and has been used extensively by medical and research centres as well as vaccine industries worldwide. However, the procedure of serotyping is labourintensive, time-consuming, requires experience and technical skill for interpretation of results and the reagents are not easily affordable, especially by developing countries. Our results show that the Denka kit has excellent correlation with the Quellung test and has several advantages: it is more rapid (mean test time, $5 \mathrm{~min}$, vs $15 \mathrm{~min}$ by Quellung test) and easy to perform, requires no special equipment and is much cheaper (0.5 US\$ per test, vs 1.4 US\$ per Quellung test).

In the past, other serotyping techniques have been described, including the counterimmunoelectrophoresis (CIEP) (Ayyagari et al., 1984), latex agglutination (LA) and coagglutination (COA) methods (Kronvall, 1973; Kaldor et al., 1988; Lalitha et al., 1996). CIEP has the drawback that the polysaccharide capsules of a small number of important serotypes fail to form precipitin lines (Henrichsen et al., 1980). The COA method for serotyping pneumococci was first developed by Kronvall (1973), who reported that it exhibited weak cross-reactions with one or more serotypes in addition to the Quellung serotype. The LA and COA methods rely on elaborate, time-consuming, self-prepared reagents (Kaldor et al., 1988). More recently, a multiplex PCR assay for determination of S. pneumoniae serotypes and serogroups has been described (Lawrence et al., 2003). This method can only determine five serotypes, 1, 3, 14, 19F and $23 \mathrm{~F}$, and serogroups 6,19 and 23 . It is not yet available for commercial use and would not be easily affordable by developing countries as it is expensive. In contrast, the Denka kit is commercially prepared, cheap and ready for use. The Denka kit offers hope to the majority of developing countries to be able to perform serotyping and obtain the appropriate conjugate vaccine, which will help to prevent high morbidity and mortality from pneumococcal infections in paediatrics (Wafula \& Onyango, 1986; Graham, 1990; Garenne et al., 1992; Onyango \& Wafula, 1995; Murray \& Lopez, 1996). It will also be very useful when conducting large epidemiological surveys. The only limitation is that the Denka kit cannot distinguish between specific types $9 \mathrm{~A}$ and $9 \mathrm{~V}$ or $24 \mathrm{~B}$ and 24F. This kit also does not include some minor nonvaccine types, such as $13,42,43,44,45$ and 48 , and some specific types, e.g. 12A, 12B, 12F, 11D, 10B, 10C and 33D. However, this point is not a major problem because the types or groups to which these specific types belong are covered in 


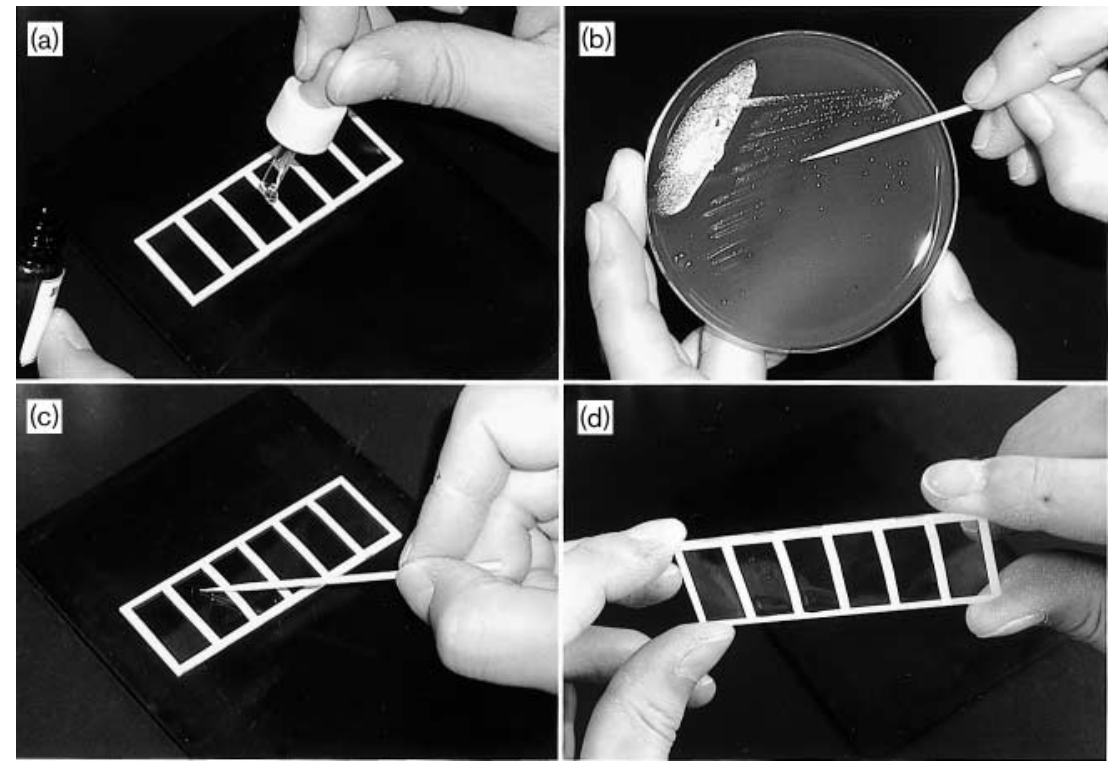

Fig. 1. Procedure of slide-agglutination by using the Denka kit. (a) Drop antiserum onto glass slide; (b) pick colonies of bacteria; (c) mix colonies with antiserum; (d) tilt glass slide back and forth and observe for agglutination.

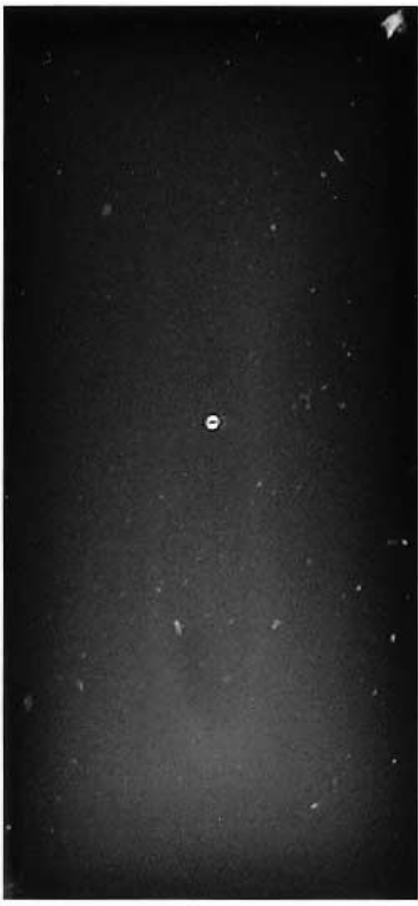

Negative

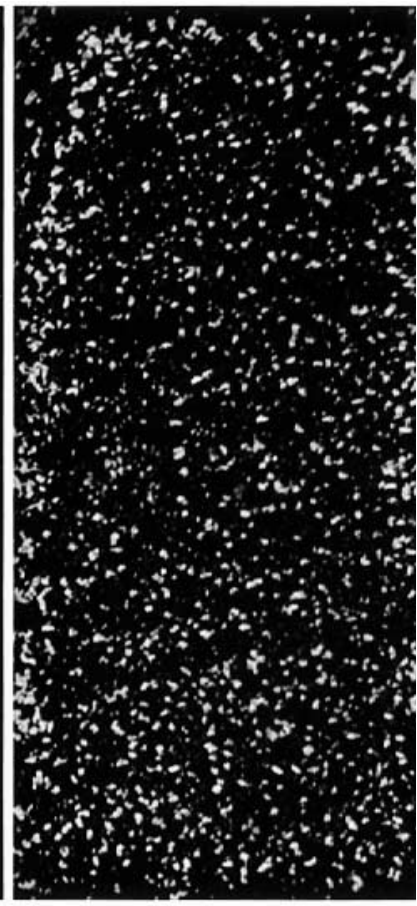

Positive

Fig. 2. Results of slide-agglutination by the Denka kit. Left, negative reaction; right, positive reaction.

the kit (Table 1). Serogroups that are not included in the new serotyping kit are minor non-vaccine types that are not important for serotyping.

Our results showed excellent correlation with the conventional method, with sensitivity and specificity of $100 \%$ by

Table 3. Determination of type or group of S. pneumoniae strains Data are no. (\%) of isolates serotyped by the Denka kit or Quellung test

\begin{tabular}{|c|c|c|}
\hline Type or group & Denka kit & Quellung test \\
\hline 3 & $31(10 \cdot 9)$ & $31(10 \cdot 9)$ \\
\hline 4 & $2(0 \cdot 7)$ & $2(0 \cdot 7)$ \\
\hline 6 & $27(9 \cdot 5)$ & $27(9 \cdot 5)$ \\
\hline 7 & $4(1 \cdot 4)$ & $4(1 \cdot 4)$ \\
\hline 8 & $6(2 \cdot 1)$ & $6(2 \cdot 1)$ \\
\hline 9 & $4(1 \cdot 4)$ & $4(1 \cdot 4)$ \\
\hline 10 & $1(0 \cdot 4)$ & $1(0 \cdot 4)$ \\
\hline 11 & $13(4 \cdot 6)$ & $13(4 \cdot 6)$ \\
\hline 12 & $4(1 \cdot 4)$ & $4(1 \cdot 4)$ \\
\hline 14 & $12(4 \cdot 2)$ & $12(4 \cdot 2)$ \\
\hline 15 & $26(9 \cdot 1)$ & $26(9 \cdot 1)$ \\
\hline 17 & $2(0 \cdot 7)$ & $2(0 \cdot 7)$ \\
\hline 18 & $15(5 \cdot 3)$ & $15(5 \cdot 3)$ \\
\hline 19 & $49(17 \cdot 2)$ & $49(17 \cdot 2)$ \\
\hline 20 & $3(1 \cdot 1)$ & $3(1 \cdot 1)$ \\
\hline 21 & $7(2 \cdot 5)$ & $7(2 \cdot 5)$ \\
\hline 23 & $39(13 \cdot 7)$ & $39(13 \cdot 7)$ \\
\hline 24 & $2(0 \cdot 7)$ & $2(0 \cdot 7)$ \\
\hline 25 & $2(0 \cdot 7)$ & $2(0 \cdot 7)$ \\
\hline 27 & $2(0 \cdot 7)$ & $2(0 \cdot 7)$ \\
\hline 28 & $1(0 \cdot 4)$ & $1(0 \cdot 4)$ \\
\hline 31 & $3(1 \cdot 1)$ & $3(1 \cdot 1)$ \\
\hline 33 & $1(0 \cdot 4)$ & $1(0 \cdot 4)$ \\
\hline 34 & $12(4 \cdot 2)$ & $12(4 \cdot 2)$ \\
\hline 35 & $7(2 \cdot 5)$ & $7(2 \cdot 5)$ \\
\hline 39 & $2(0 \cdot 7)$ & $2(0 \cdot 7)$ \\
\hline 40 & $1(0 \cdot 4)$ & $1(0 \cdot 4)$ \\
\hline 41 & $5(1 \cdot 8)$ & $5(1 \cdot 8)$ \\
\hline 46 & $1(0 \cdot 4)$ & $1(0 \cdot 4)$ \\
\hline Total & $285(100)$ & $285(100)$ \\
\hline
\end{tabular}


Table 4. Determination of specific types of $S$. pneumoniae strains

Data are no. (\%) of isolates serotyped by the Denka kit or Quellung test

\begin{tabular}{|c|c|c|}
\hline Specific type & Denka kit & Quellung test \\
\hline $6 \mathrm{~A}$ & $14(7 \cdot 4)$ & $14(7 \cdot 4)$ \\
\hline $6 \mathrm{~B}$ & $14(7 \cdot 4)$ & $14(7 \cdot 4)$ \\
\hline $7 \mathrm{~A}$ & $1(0 \cdot 5)$ & $1(0 \cdot 5)$ \\
\hline $7 \mathrm{C}$ & $3(1 \cdot 6)$ & $3(1 \cdot 6)$ \\
\hline $9 \mathrm{~A} / 9 \mathrm{~V}$ & $1(0 \cdot 5)$ & \\
\hline $9 \mathrm{~V}$ & & $1(0 \cdot 5)$ \\
\hline $9 \mathrm{~L}$ & $1(0 \cdot 5)$ & $1(0 \cdot 5)$ \\
\hline $9 \mathrm{~N}$ & $2(1 \cdot 1)$ & $2(1 \cdot 1)$ \\
\hline $10 \mathrm{~A}$ & $1(0 \cdot 5)$ & $1(0 \cdot 5)$ \\
\hline $11 \mathrm{~A}$ & $11(5 \cdot 8)$ & $11(5 \cdot 8)$ \\
\hline $11 \mathrm{~B}$ & $2(1 \cdot 1)$ & $2(1 \cdot 1)$ \\
\hline $11 \mathrm{C}$ & $2(1 \cdot 1)$ & $2(1 \cdot 1)$ \\
\hline $15 \mathrm{~A}$ & $8(4 \cdot 2)$ & $8(4 \cdot 2)$ \\
\hline $15 B$ & $3(1 \cdot 6)$ & $3(1 \cdot 6)$ \\
\hline $15 \mathrm{C}$ & $9(4 \cdot 7)$ & $9(4 \cdot 7)$ \\
\hline $15 \mathrm{~F}$ & $5(2 \cdot 6)$ & $5(2 \cdot 6)$ \\
\hline $18 \mathrm{~A}$ & $1(0 \cdot 5)$ & $1(0 \cdot 5)$ \\
\hline $18 \mathrm{~B}$ & $2(1 \cdot 1)$ & $2(1 \cdot 1)$ \\
\hline $18 \mathrm{C}$ & $1(0 \cdot 5)$ & $1(0 \cdot 5)$ \\
\hline $18 \mathrm{~F}$ & $11(5 \cdot 8)$ & $11(5 \cdot 8)$ \\
\hline $19 A$ & $4(2 \cdot 1)$ & $4(2 \cdot 1)$ \\
\hline 19B & $3(1 \cdot 6)$ & $3(1 \cdot 6)$ \\
\hline $19 \mathrm{~F}$ & $41(21 \cdot 6)$ & $41(21 \cdot 6)$ \\
\hline $23 \mathrm{~A}$ & $6(3 \cdot 1)$ & $6(3 \cdot 1)$ \\
\hline $23 \mathrm{~B}$ & $1(0 \cdot 5)$ & $1(0 \cdot 5)$ \\
\hline $23 \mathrm{~F}$ & $32(16 \cdot 8)$ & $32(16 \cdot 8)$ \\
\hline $24 \mathrm{~B}$ & & $2(1 \cdot 1)$ \\
\hline $24 \mathrm{~B} / 24 \mathrm{~F}$ & $2(1 \cdot 1)$ & \\
\hline $33 \mathrm{~F}$ & $1(0 \cdot 5)$ & $1(0 \cdot 5)$ \\
\hline $35 \mathrm{~B}$ & $1(0 \cdot 5)$ & $1(0 \cdot 5)$ \\
\hline $35 \mathrm{C}$ & $4(2 \cdot 1)$ & $4(2 \cdot 1)$ \\
\hline $35 \mathrm{~F}$ & $2(1 \cdot 1)$ & $2(1 \cdot 1)$ \\
\hline Total & $191(100)$ & $191(100)$ \\
\hline
\end{tabular}

using the Denka kit. In conclusion, the Denka kit is easy to use, simple, cheap and reliable. This kit may be very useful, especially for fieldworkers in developing countries who are involved in large epidemiological studies or vaccine development.

\section{ACKNOWLEDGEMENTS}

The authors are grateful to Denka Seiken Co. Ltd, Tokyo, Japan, for supplying the new S. pneumoniae serotyping kit (Denka kit) used in this study. We thank Dr Ichiro Itoda and Dr Takeshi Yasunami, Department of Infectious Diseases, Tokyo Women's Medical University, for their assistance with technical computer work. M. A. M. was supported by the Japan International Cooperation Agency (Doctor course in tropical medicine).

\section{REFERENCES}

Ayyagari, A., Kumar, L., Agarwal, K. C., Ganju, S., Sharma, P. \& Pancholi, V. (1984). Prevalence of serotypes of Streptococcus pneumoniae in patients in and around Chandigarh. Indian J Med Res 79, 174-177.

Brooks, G. F., Butel, J. S. \& Morse, A. S. (1998). The Streptococci. In Jawetz, Melnick and Adelberg's Medical Microbiology, 21st edn, pp. 212-213. Stamford, CT: Appleton Lange.

Cant, A. J. (2002). Community-acquired pneumonia in children. In Respiratory Infections: Proceedings of the Eighth Liverpool Tropical School Bayer Symposium of Microbial Disease held on 3 February 2001; edited by C. A. Hart, N. J. Beeching \& B. I. Duerden. J Med Microbiol 51, 903-914.

Doern, G. V., Ferraro, M. J., Gilligan, P. H., Janda, J. M. \& Graevenitz, A. (1999). Streptococcus. In Manual of Clinical Microbiology, 7th edn, pp. 286-288. Edited by P. R. Murray, E. J. Baron, M. A. Pfaller, F. C. Tenover \& R. H. Yolken. Washington, DC: American Society for Microbiology.

Garenne, M., Ronsmans, C. \& Campbell, H. (1992). The magnitude of mortality from acute respiratory infections in children under five years in developing countries. World Health Stat Q 45, 180-191.

Graham, N. M. H. (1990). The epidemiology of acute respiratory infections in children and adults: a global perspective. Epidemiol Rev 12, 149-178.

Hausdorff, W. P., Bryant, J., Paradiso, P. R. \& Siber, G. R. (2000). Which pneumococcal serogroups cause the most invasive disease: implications for conjugate vaccine formulation and use, part I. Clin Infect Dis 30, $100-121$.

Hausdorff, W. P., Yothers, G., Dagan, R. \& 11 other authors (2002). Multinational study of pneumococcal serotypes causing acute otitis media in children. Pediatr Infect Dis J 21, 1008-1016.

Henrichsen, J., Berntsson, E. \& Kaijser, B. (1980). Comparison of counterimmunoelectrophoresis and the capsular reaction test for typing of pneumococci. J Clin Microbiol 11, 589-592.

Joloba, M. L., Windau, A., Bajaksouzian, S., Appelbaum, P. C., Hausdorff, W. P. \& Jacobs, M. R. (2001). Pneumococcal conjugate vaccine serotypes of Streptococcus pneumoniae isolates and the antimicrobial susceptibility of such isolates in children with otitis media. Clin Infect Dis 33, 1489-1494.

Kaldor, J., Asznowicz, R. \& Dwyer, B. (1988). Serotyping of Streptococcus pneumoniae by latex agglutination. Pathology 20, 45-47.

Kronvall, G. (1973). A rapid slide-agglutination method for typing pneumococci by means of specific antibody adsorbed to protein Acontaining staphylococci. J Med Microbiol 6, 187-190.

Lalitha, M. K., Pai, R., John, T. J., Thomas, K., Jesudason, M. V., Brahmadathan, K. N., Sridharan, G. \& Steinhoff, M. C. (1996). Serotyping of Streptococcus pneumoniae by agglutination assays: a cost-effective technique for developing countries. Bull WHO 74, 387-390.

Lawrence, E. R., Griffiths, D. B., Martin, S. A., George, R. C. \& Hall, L. M. C. (2003). Evaluation of semiautomated multiplex PCR assay for determination of Streptococcus pneumoniae serotypes and serogroups. J Clin Microbiol 41, 601-607.

Lund, E. \& Henrichsen, J. (1978). Laboratory diagnosis, serology and epidemiology of Streptococcus pneumoniae. In Methods in Microbiology, vol. 12, pp. 244-255. London: Academic Press.

Murray, C. J. L. \& Lopez, A. D. (1996). The Global Burden of Disease: a Comprehensive Assessment of Mortality and Disability from Diseases, Injuries, and Risk Factors in 1990 and Projected to 2020. Cambridge, MA: World Health Organization.

Nagai, K., Shibasaki, Y., Hasegawa, K., Davies, T. A., Jacobs, M. R., Ubukata, K. \& Appelbaum, P. C. (2001). Evaluation of PCR primers to 
screen for Streptococcus pneumoniae isolates and $\beta$-lactam resistance, and to detect common macrolide resistance determinants. J Antimicrob Chemother 48, 915-918.

Onyango, F. E. \& Wafula, E. M. (1995). Acute respiratory infections. In Primary Health Care: a Manual for Medical Students and Other Health Workers, 2nd edn, pp. 83-97. Edited by K. Mukelabai, N. O. Bwibo \& F. E. Onyango. Nairobi, Kenya: UNICEF.
Roberts, R. B. (1979). Streptococcus pneumoniae. In Principles and Practice of Infectious Disease, pp. 1589-1604. Edited by G. L. Mandell, R. G. Douglas and J. E. Bennett. New York: Wiley.

Sorensen, U. B. (1993). Typing of pneumococci by using 12 pooled antisera. J Clin Microbiol 31, 2097-2100.

Wafula, E. M. \& Onyango, F. E. (1986). Acute respiratory infections in developing countries. East Afr Med J 63, 211. 